International Journal of Electrical Engineering and Technology (IJEET)

Volume 12, Issue 9, September 2021, pp. 9-19, Article ID: IJEET_12_09_002

Available online at https://iaeme.com/Home/issue/IJEET? Volume $=12 \&$ Issue $=9$

ISSN Print: 0976-6545 and ISSN Online: 0976-6553

DOI: https://doi.org/10.34218/IJEET.12.9.2021.002

\title{
DESIGN AND IMPLEMENTATION OF FIR LOW PASS FILTER - A CASE STUDY ON THE EFFECTS OF INITIAL COEFFICIENT VALUE TO ACHIEVE THE DESIRED FILTER OUTPUT
}

\author{
Bimal Pal \\ Department of Computer Science and Engineering, \\ Government College of Engineering and Ceramic Technology, Kolkata, \\ West Bengal, India
}

\begin{abstract}
The usage of filter is inevitable in most of the electronics devices to reject all unwanted high frequencies of electrical signal \& pass the desired signal and for this purpose a precision filter is to be used in the input stage of the device. In an $R-C L$ Low Pass Filter capacitive reactance varies with the applied frequency of the input signal. When the applied frequency of the input signal increases the capacitive reactance is decreased and high frequency signal is bypassed to the ground through the capacitor. But in the case of FIR Low Pass Filter, the unwanted high frequency signal is suppressed with the help of filter coefficients. The desired output of an FIR Low Pass Filter can be obtained when the sample values of the input signal are instantaneously processed with the corresponding coefficient values. This case study shows that the initial value $h(0)$ of the filter coefficients has a vital role to achieve the desired filter output. Though initial value $h(0)$ is undefined and can be calculated by L. Hospitals' Rule after multiplication with a window function.
\end{abstract}

Key words: Coefficient, convolution, cut-off frequency, filter order, impulse response

Cite this Article: Bimal Pal. Design and Implementation of Fir Low Pass Filter - A Case Study on the Effects of Initial Coefficient Value to Achieve the Desired Filter Output. International Journal of Electrical Engineering and Technology (IJEET). 12(9). 2021, pp. 9-19.

https://iaeme.com/Home/issue/IJEET?Volume $=12 \&$ Issue $=9$

\section{INTRODUCTION}

The main task for designing and implementation of an FIR filter is to determine the Filter Coefficients $h(n)$ where $n=0,1,2, \ldots M-1$ and $M$ is the number of coefficients or called the order of the filter [1],[2]. 
It is assumed that $\mathrm{H}_{\mathrm{d}}\left(\mathrm{e}^{\mathrm{jw}}\right)$ is the desired frequency response of an ideal Low Pass Filter and can be expressed as

$$
\mathrm{H}_{\mathrm{d}}\left(\mathrm{e}^{\mathrm{jw}}\right)=\sum_{n=-\infty}^{\infty} h_{d}(n) \times \mathrm{e}^{\mathrm{jwn}}
$$

Here $h_{d}(n)$ has an infinite-duration impulse response sequence. For the implementation of an FIR filter, the impulse response sequence of infinite duration is truncated i.e. cropped at some point to obtain the desired finite-duration impulse response [3].

The impulse response of an ideal Low Pass Filter $h_{d}(n)$ is obtained by inverse Fourier Transform. The magnitude response of an ideal Low Pass Filter is shown in Fig.1.

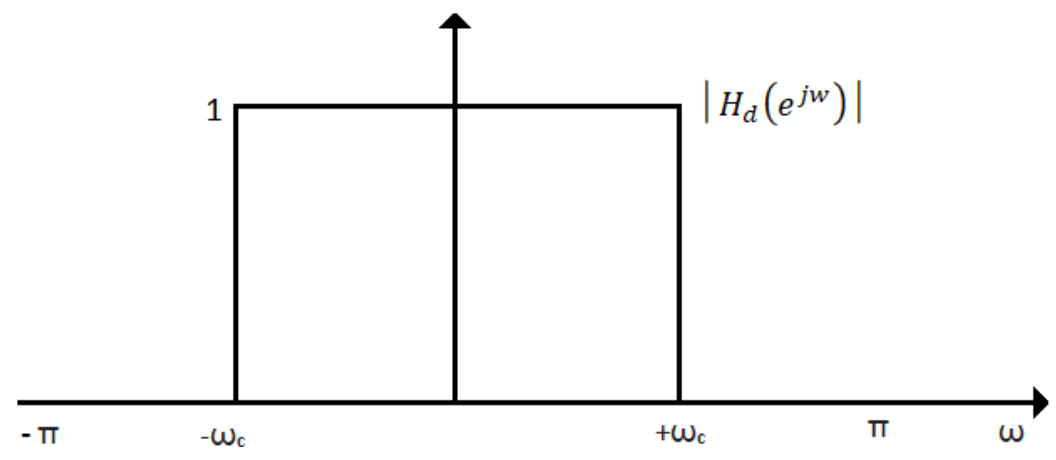

Figure 1 Magnitude response of ideal Low Pass Filter

Now, $\mathrm{h}_{\mathrm{d}}(\mathrm{n})=\int_{-\pi}^{\pi} H_{d}\left(e^{j w}\right) \times \mathrm{e}^{\mathrm{jwn}} \mathrm{d} \omega$

Hence, $\mathrm{h}_{\mathrm{d}}(\mathrm{n})=\frac{\sin (\omega c n)}{\pi n}=\frac{\sin 2 \pi \frac{f c \times n}{F s}}{\pi n}$

where $f_{c}$ is the cut-off frequency, $F_{s}$ is the sampling frequency and $n$ is the length of the filter.

$\mathrm{h}_{\mathrm{d}}(0)$ is calculated by L. Hospitals' Rule and its value is $\frac{2 f c}{F s}$

So, this design equation can also be represented as

$$
\begin{gathered}
\mathrm{h}_{\mathrm{d}}(\mathrm{n})=\frac{2 f c}{F s} \times \frac{\sin 2 \pi n f c / F s}{2 \pi n f c / F s}, \text { for } \mathrm{n}>0 \\
=\frac{2 f c}{F s}, \quad \text { for } \mathrm{n}=0
\end{gathered}
$$

In reality, the desired impulse response $h_{d}(n)$ is multiplied with the desired window sequence, say $w_{h}(n)$, for getting the coefficients of the filter (in this design Hamming Window is chosen).

The formula for Hamming Window Function (causal signal),

$$
\begin{aligned}
\mathrm{W}_{\mathrm{h}}(\mathrm{n}) & =0.54-0.46 \cos \frac{2 \pi n}{M-1} \quad \text { for } 0 \leq \mathrm{n} \leq \mathrm{M}-1 \\
= & 0, \text { otherwise }
\end{aligned}
$$

where $\mathrm{n}=0,1,2, \ldots \mathrm{M}-1$ and $\mathrm{M}$ is the order of the filter.

So, Filter Coefficients can be computed as $h(n)=h_{d}(n) \times w_{h}(n)$

For linear phase FIR filter $h_{d}(n)$ can also be computed as $h_{d}(n)=\frac{\sin \left[w c\left(n-\frac{M}{2}\right)\right]}{\pi\left(n-\frac{M}{2}\right)}[6]$, [7].

\subsection{Estimation of Filter Order (M)}

The order of the filter is inversely proportional to the transition bandwidth. The degree of precision of a filter mainly depends on the order of the filter and the degree of precision improves as the order of the filter increases [8]. 
A sharp cut-off FIR filter with a narrow transition band requires the large number of coefficients. There are many methods for determining the order of the filter. But all methods have their corresponding advantages and disadvantages.

A formula developed by Kaiser for the estimation of the order of the filter can be written as

$\mathrm{M} \cong \frac{-20 \log _{10} \sqrt{(\partial p \partial s)}-13}{14.6\left[\frac{f s-f p}{F s}\right]}$

It is assumed that passband ripple $\partial p=0.002$ and stopband ripple $\partial \mathrm{s}=0.001$. So, when passband frequency fp $=500 \mathrm{~Hz}$, stopband frequency $\mathrm{fs}=550 \mathrm{~Hz}$ and sampling frequency $\mathrm{Fs}=$ $8000 \mathrm{~Hz}$,

The order of filter $M \cong \frac{-20 \log _{10} \sqrt{0.002 \times 0.001}-13}{14.6\left[\frac{50}{8000}\right]}=482$

It is observed that

a) filter order increases when $\partial p$ and $\partial s$ increases.

b) filter order increases when transition bandwidth becomes small

c) filter order increases when sampling frequency is high.

In practice, based on passband frequency and sampling frequency filter order is approximated to a sufficiently less value with some compromise on the degree of precision of filter. On the other hand, when the order of the filter is increased the output gain of the filter is decreased.

For a low pass filter increased main lobe width corresponds to increased transition bandwidth between the passband and the stopband, whereas decreased side lobe levels correspond to smaller ripples (more rejection) in the filter stopband and passband [9].

\section{METHOD}

In this practical approach, coefficients have been generated for $11^{\text {th }}$ order, $23^{\text {rd }}$ order, $33^{\text {rd }}$ order and $53^{\text {rd }}$ order filter with cut-off frequency $500 \mathrm{~Hz}$ and sampling frequency $8000 \mathrm{~Hz}$.

Input signal [Fig. 2] for this FIR low pass filter has been created by concatenating 32 samples of $250 \mathrm{~Hz}, 32$ samples of $1000 \mathrm{~Hz}$ and 32 samples of $500 \mathrm{~Hz}$ sinusoidal signals assuming $8000 \mathrm{~Hz}$ sampling frequency. The mixed signal consists of 96 sample values and has been used here as the input signal of the filter. The input signal and output signal of this FIR filter is saved as DAT file of 96 values and by one zero padding at the end, the length has been made 97 values to plot the input signal and output signal of the FIR Filter up to the baseline (isoelectrical line). Here the design has been made to attenuate $1000 \mathrm{~Hz}$ signal and pass $250 \mathrm{~Hz}$ \& $500 \mathrm{~Hz}$ signal from the output of the filter.

The coefficient values and their lengths are different according to the order of the filter, though the coefficient value does not depend upon the order of the filter. The coefficient value depends upon the cut-off frequency and the sampling frequency of the FIR filter. The input signal values for this experiment are fixed and total ninety seven input signal values have been used here.

The ninety seven input signal sample values are $[0.000000,0.195090,0.382683,0.555570,0.707107,0.831470,0.923880,0.980785,1.000000,0.980785,0$. $923880,0.831470,0.707107,0.555570,0.382683,0.195090,-0.000000,-0.195090,-0.382684,-0.555570,-$ $0.707107,-0.831470,-0.923880,-0.980785,-1.000000,-0.980785,-0.923880,-0.831470,-0.707107,--$ 0.555570,-0.382683,-0.195090,0.000000,0.707107,1.000000,0.707107,-0.000000,0.707107,1.000000, 0.707107,0.000000,0.707107,1.000000,0.707107,0.000000,0.707107,1.000000,0.707107,0.000000,0. $707107,1.000000,0.707106,0.000000,0.707107,1.000000,0.707106,0.000001,0.707107,1.000000,0.70$ $7106,0.000001,0.707107,1.000000,0.707106,0.000000,0.382683,0.707107,0.923880,1.000000,0.9238$ 
$80,0.707107,0.382683,-0.000000,-0.382684,-0.707107,0.923880,1.000000,0.923880,0.707107$, $0.382683,0.000000,0.382684,0.707107,0.923880,1.000000,0.923879,0.707107,0.382683,-0.000000,-$ $0.382684,-0.707107,-0.923880,-1.000000,-0.923879,-0.707107,-0.382683,0.000000]$

Using the above mentioned sample values the input signal waveform for the FIR filter has been plotted for this experiment.

The input signal waveform is -

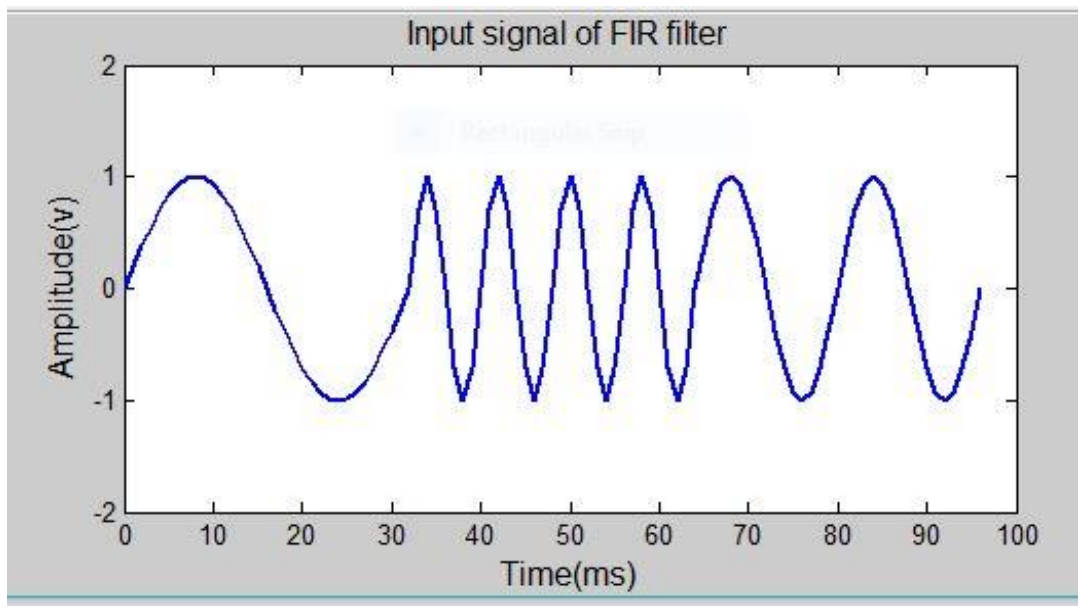

Figure 2 Input waveform consists of 97 sample values.

The waveform of the input signal is a mixed signal of $250 \mathrm{~Hz}, 1000 \mathrm{~Hz}$ and $500 \mathrm{~Hz}$ sinusoidal signal.

An FIR filter can be implemented by using the convolution sum formula and the output of the FIR filter $y(n)$ can be obtained from the convolution equation when the values of coefficients are described by $\mathrm{h}(\mathrm{k})$ and input signal values are described by $\mathrm{x}(\mathrm{n})$. In the convolution sum operation, the coefficient values are gradually incremented and the sample values of the input signal are correspondingly decremented during multiplication operation. The coefficients are always adjusted at each sample point to make the error in the output as small as possible. For a causal FIR system output signal depends on the present and past input signal values. By the convolution formula, the response of an FIR filter can be computed by the equation

$$
\mathrm{y}(\mathrm{n})=\sum_{k=0}^{M-1} h(k) x(n-k)
$$

where $\mathrm{M}$ is the order of filter and $\mathrm{n}$ is the length of the input signal [10].

The duration of the output sequence $\mathrm{y}(\mathrm{n})$ is also sometimes computed assuming $n=n+(M-1)$.

This is done by padding $(M-1)$ numbers zero with the $x(n)$ sequence. So, for $11^{\text {th }}$ order FIR filter, in this case the output sequence $y(n)$ will be $y(0)$ to $y(106)$ and for the $23^{\text {rd }}$ order filter, the output sequence will be $\mathrm{y}(0)$ to $\mathrm{y}(118)$ and so on.

But when $(\mathrm{M}-1)$ numbers zero are padded, then processed output sequences will be larger than the input signal sequences and will not match with the sequences of the input signal $x(n)$. So, in this work filter operation has been done without (M-1) zero padding.

\section{RESULT}

In this work all the mathematical calculations i.e. coefficient values calculation, sample values calculation of the input signal and FIR filter output values calculation has been done by Cprogram and plotting of input \& output waveforms has been done by MATLAB. 


\section{Case-1 [Filter Order 11]:}

When the order of the filter is 11 with cut-frequency of the FIR low pass filter is $500 \mathrm{~Hz}$ and the sampling frequency is $8000 \mathrm{~Hz}$.

1a) Initial coefficient value $h(0)$ has been calculated by $h_{d}(0) \times w_{h}(0)$, assuming $h_{d}(0)=\frac{2 f c}{F s}$ and $w_{h}(0)=0.54-0.46$

Here the coefficients for the $11^{\text {th }}$ order filter are -

$\mathrm{h}(0)=0.010000, \mathrm{~h}(1)=0.020446, \mathrm{~h}(2)=0.044774, \mathrm{~h}(3)=0.066869, \mathrm{~h}(4)=0.072586, \mathrm{~h}(5)=$ $0.058816, \mathrm{~h}(6)=0.034218, \mathrm{~h}(7)=0.011871, \mathrm{~h}(8)=0.000000, \mathrm{~h}(9)=-0.0022, \mathrm{~h}(10)=-$ 0.001801

Using the convolution sum formula the output values of the $11^{\text {th }}$ order FIR filter will be as per the following equations

$$
\begin{aligned}
& y(0)=h(0) x(0) \\
& y(1)=h(0) x(1)+h(1) x(0) \\
& y(2)=h(0) x(2)+h(1) x(1)+h(2) x(0) \\
& y(96)=h(0) x(96)+h(1) x(95)+h(2) x(94)+\cdots+h(10) x(86)
\end{aligned}
$$

After computation, the output values will be $[\mathrm{y}(0)=0.000000, \mathrm{y}(1)=0.001951, \mathrm{y}(2)=0.007816, \mathrm{y}(3)=0.022115, \ldots, \mathrm{y}(93)=-0.128559$, $\mathrm{y}(94)=-0.205705, \mathrm{y}(95)=-0.251534, \mathrm{y}(96)=0.000000]$

The waveform is -

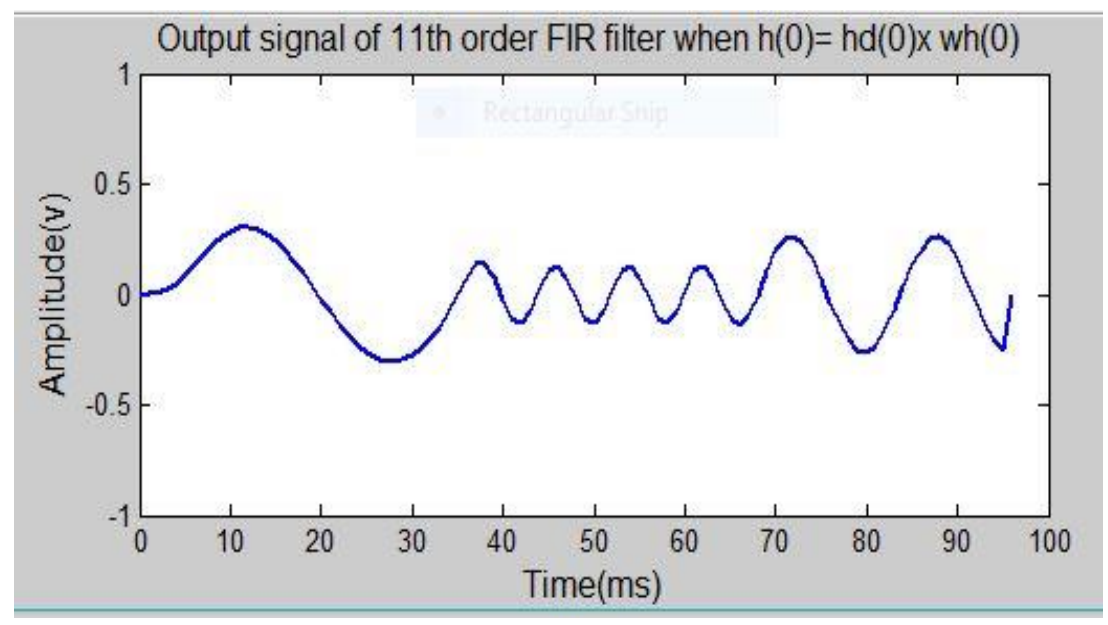

Figure 3a Output waveform of $11^{\text {th }}$ order low pass filter

$\left[\mathrm{h}(0)=\mathrm{h}_{\mathrm{d}}(0) \times \mathrm{w}_{\mathrm{h}}(0)\right]$

1b) Here initial coefficient value $h(0)$ has been calculated only by $h_{d}(0)$ without multiplication of window sequence.

The coefficient values are $\mathrm{h}(0)=0.125000, \mathrm{~h}(1)=0.020446, \mathrm{~h}(2)=0.044774, \mathrm{~h}(3)=0.066869, \mathrm{~h}(4)=0.072586, \mathrm{~h}(5)=$ $0.058816, h(6)=0.034218, h(7)=0.011871, h(8)=0.000000, h(9)=-0.0022, h(10)=-$ 0.001801

Using the convolution sum formula the output values of the $11^{\text {th }}$ order FIR filter $y(n)$ can be obtained for $h(0)=h_{d}(0)$ as-

$[\mathrm{y}(0)=0.000000, \mathrm{y}(1)=0.024386, \mathrm{y}(2)=0.051824, \mathrm{y}(3)=0.086006, \ldots, \mathrm{y}(93)=-0.234805$, $\mathrm{y}(94)=-0.287022, \mathrm{y}(95)=-0.295543, \mathrm{y}(96)=0.000000]$ 
The waveform is -

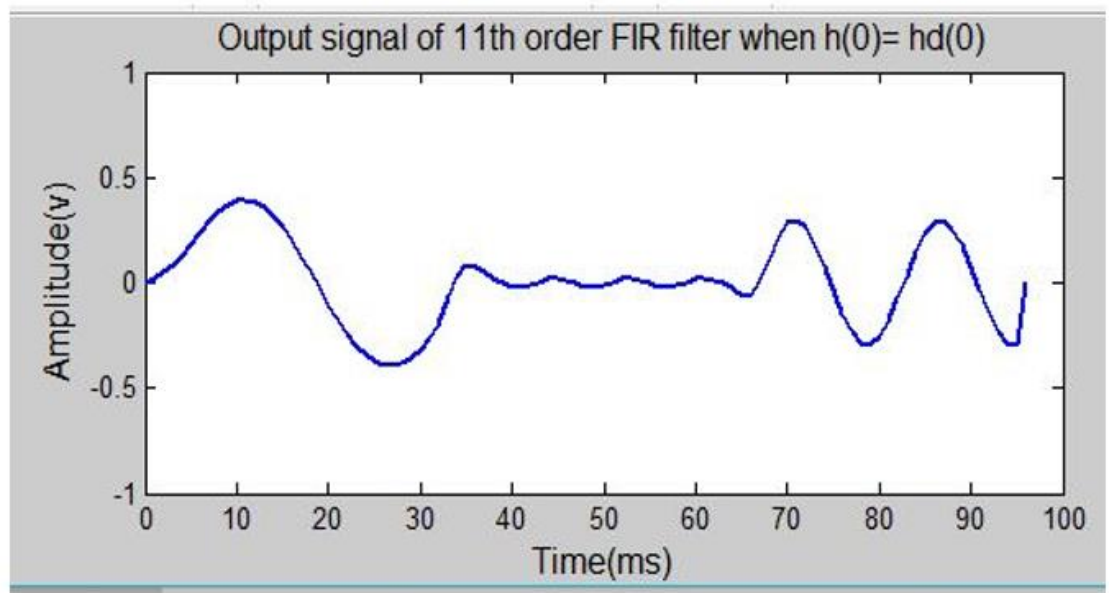

Figure 3b Output waveform of $11^{\text {th }}$ order low pass filter

$\left[\mathrm{h}(0)=\mathrm{h}_{\mathrm{d}}(0)\right]$

In this Case-1, it has been observed that the filter works better when the first coefficient value $h(0)$ is taken as $h_{d}(0)$ only.

\section{Case-2 [Filter Order 23]:}

When the order of the filter is 23 with cut-frequency of the FIR filter is $500 \mathrm{~Hz}$ and the sampling frequency is $8000 \mathrm{~Hz}$.

2a) Initial coefficient value $h(0)$ has been calculated by $h_{d}(0) \times w_{h}(0)$, assuming $h_{d}(0)=\frac{2 f c}{F s}$ and $w_{h}(0)=0.54-0.46$

Here the coefficient values from $h(0)$ to $h(22)$ for the $23^{\text {rd }}$ order FIR low pass filter are $[\mathrm{h}(0)=0.010000, \mathrm{~h}(1)=0.012015, \mathrm{~h}(2)=0.017221, \mathrm{~h}(3)=0.023405, \ldots, \mathrm{h}(19)=0.003696$, $\mathrm{h}(20)=0.002435, \mathrm{~h}(21)=0.001381, \mathrm{~h}(22)=0.000818]$

Using the convolution sum formula the output values of the 23rd order FIR filter $y(n)$ can be obtained for $h(0)=h_{d}(0) \times w_{h}(0)$ as-

$[\mathrm{y}(0)=0.000000, \mathrm{y}(1)=0.001951, \mathrm{y}(2)=0.006171, \mathrm{y}(3)=0.013513, \ldots, \mathrm{y}(93)=-0.109760$, $\mathrm{y}(94)-0.178169, \mathrm{y}(95)=-0.219454, \mathrm{y}(96)=0.000000$ ]

The waveform is -

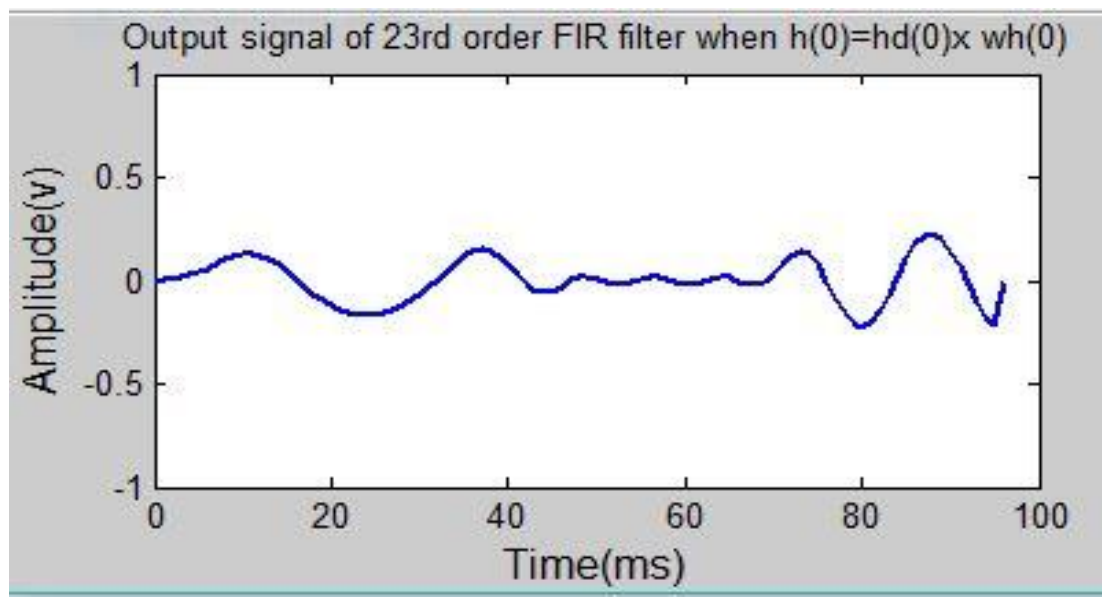

Figure 4a Output signal of 23rd order low pass filter 


$$
\left[\mathrm{h}(0)=\mathrm{h}_{\mathrm{d}}(0) \times \mathrm{w}_{\mathrm{h}}(0)\right]
$$

2b) Here initial coefficient value $h(0)$ has been calculated only by $h_{d}(0)$ without multiplication of window sequence.

The coefficient values from $\mathrm{h}(0)$ to $\mathrm{h}(22)$ for the $23^{\text {rd }}$ order FIR low pass filter are $[\mathrm{h}(0)=0.125000, \mathrm{~h}(1)=0.012015, \mathrm{~h}(2)=0.017221, \mathrm{~h}(3)=0.023405, \ldots, \mathrm{h}(19)=0.003696$, $\mathrm{h}(20)=0.002435, \mathrm{~h}(21)=0.001381, \mathrm{~h}(22)=0.000818]$

Using the convolution sum formula the output values of the 23rd order FIR filter $y(n)$ can be obtained for $h(0)=h_{d}(0)$ as -

$[\mathrm{y}(0)=0.000000, \mathrm{y}(1)=0.024386, \mathrm{y}(2)=0.050179, \mathrm{y}(3)=0.077404, \ldots, \mathrm{y}(19)=-0.216006$, $\mathrm{y}(20)=-0.259487, \mathrm{y}(21)=-0.263463, \mathrm{y}(22)=0.000000]$

The waveform is -

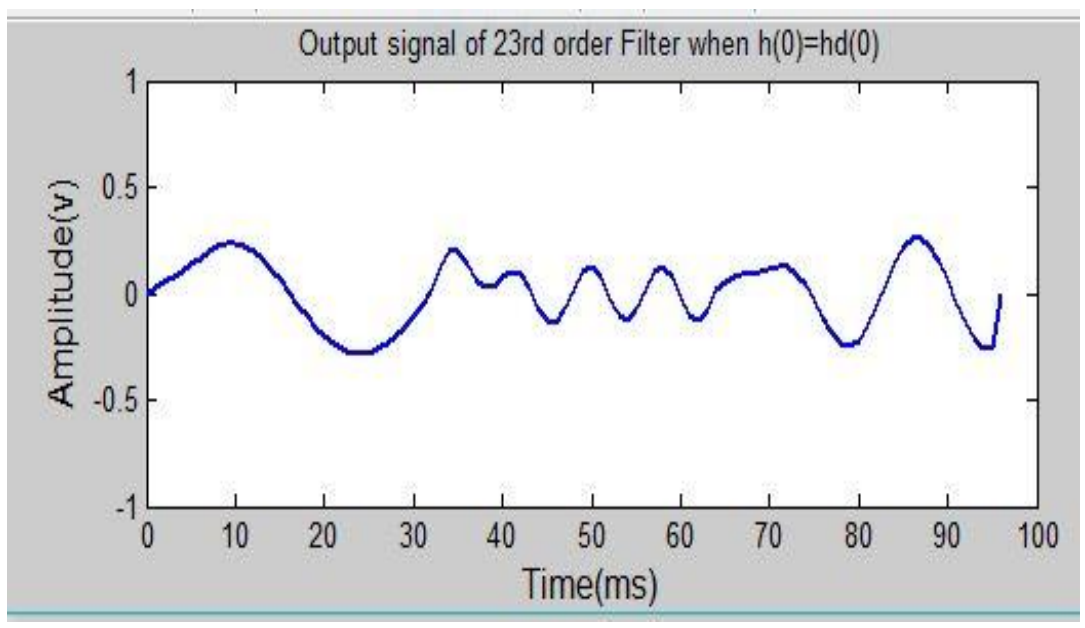

Figure 4b Output waveform of 23rd order low pass filter

$\left[\mathrm{h}(0)=\mathrm{h}_{\mathrm{d}}(0)\right]$

In this Case-2, it has been observed that the $23^{\text {rd }}$ order FIR filter works better when the first coefficient value $h(0)$ is taken as $h_{d}(0) \times w_{h}(0)$.

\section{Case-3 [Filter Order 33]:}

When the order of the filter is 33 with cut-frequency of the FIR filter is $500 \mathrm{~Hz}$ and the sampling frequency is $8000 \mathrm{~Hz}$.

3a) Initial coefficient value $h(0)$ has been calculated by $h_{d}(0) \times w_{h}(0)$, assuming $h_{d}(0)=\frac{2 f c}{F s}$ and $w_{h}(0)=0.54-0.46$

Here the coefficient values from $\mathrm{h}(0)$ to $\mathrm{h}(32)$ for the $33^{\text {rd }}$ order FIR low pass filter are $[\mathrm{h}(0)=0.010000, \mathrm{~h}(1)=0.010822, \mathrm{~h}(2)=0.012944, \mathrm{~h}(3)=0.015442, \ldots, \mathrm{y}(29)=-0.001597$, $\mathrm{y}(30)=-0.000863, \mathrm{y}(31)=-0.000349, \mathrm{y}(32)=-0.000000]$

Using the convolution sum formula the output values of the 33rd order FIR filter $y(n)$ can be obtained for $h(0)=h_{d}(0) \times w_{h}(0)$ as-

$[\mathrm{y}(0)=0.000000, \mathrm{y}(1)=0.001951, \mathrm{y}(2)=0.005938, \mathrm{y}(3)=0.012222, \ldots, \mathrm{y}(93)=-0.110044$, $\mathrm{y}(94)=-0.179216, \mathrm{y}(95)=-0.220931, \mathrm{y}(96)=0.000000]$ 
The waveform is -

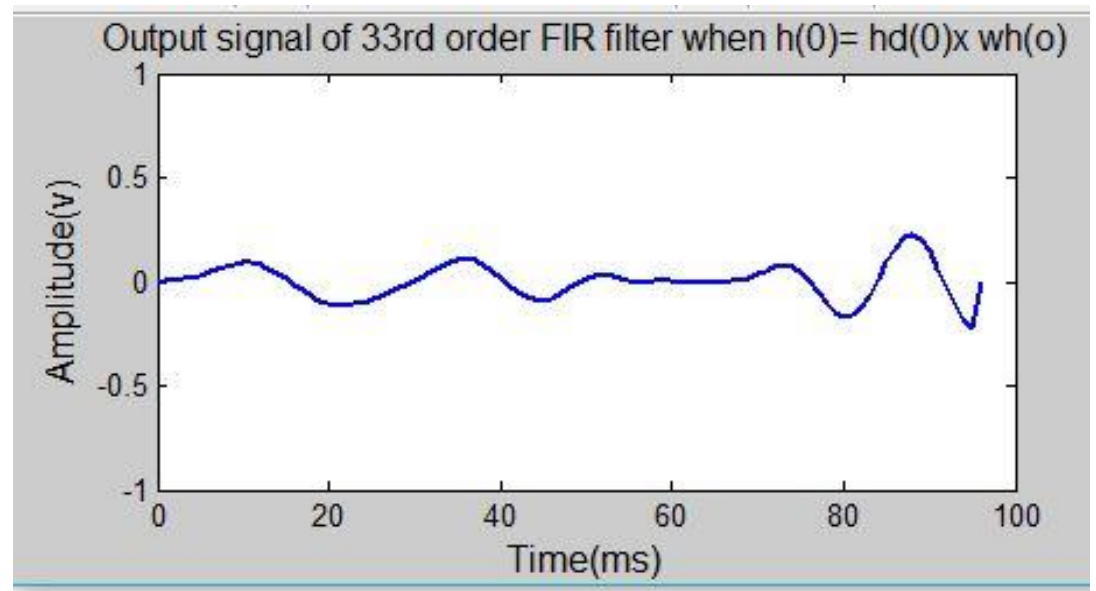

Figure 5a Output waveform of 33rd order low pass filter

$\left[\mathrm{h}(0)=\mathrm{h}_{\mathrm{d}}(0) \times \mathrm{w}_{\mathrm{h}}(0)\right]$

3b) Here initial coefficient value $h(0)$ has been calculated only by $h_{d}(0)$ without multiplication of window sequence.

The coefficient values from $\mathrm{h}(0)$ to $\mathrm{h}(32)$ for the $33^{\text {rd }}$ order FIR low pass filter are -

$[\mathrm{h}(0)=0.125000, \mathrm{~h}(1)=0.010822, \mathrm{~h}(2)=0.012944, \mathrm{~h}(3)=0.015442, \ldots, \mathrm{y}(29)=-0.001597$, $\mathrm{y}(30)=-0.000863, \mathrm{y}(31)=-0.000349, \mathrm{y}(32)=-0.000000]$

Using the convolution sum formula the output values of the 33rd order FIR filter $y(n)$ can be obtained for $h(0)=h_{d}(0)$ as -

$[\mathrm{y}(0)=0.000000, \mathrm{y}(1)=0.024386, \mathrm{y}(2)=0.049947, \mathrm{y}(3)=0.076113, \ldots, \mathrm{y}(93)-0.216290$, $\mathrm{y}(94)=-0.260533, \mathrm{y}(95)=-0.264939, \mathrm{y}(96)=0.000000]$

The waveform is -

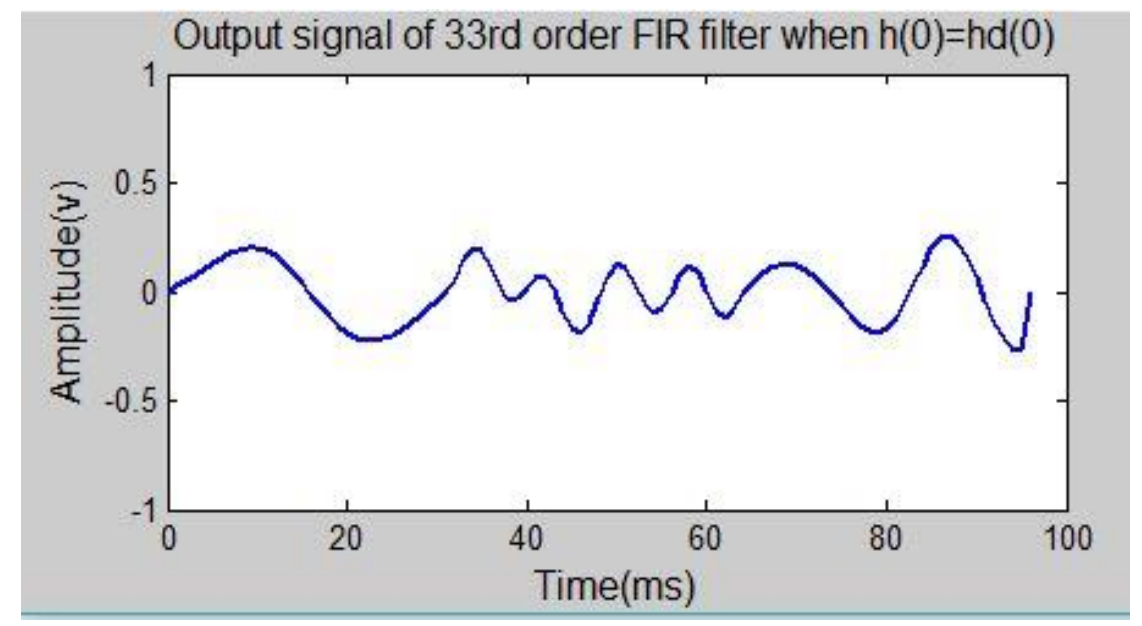

Figure 5b Output waveform of 33rd order low pass filter

$\left[\mathrm{h}(0)=\mathrm{h}_{\mathrm{d}}(0)\right]$

In this Case-3, it has been observed that the filter works better when the first coefficient value $h(0)$ is taken as $h_{d}(0) \times w_{h}(0)$. 


\section{Case-4 [Filter Order 53]}

When the order of the filter is 53 with cut-frequency of the FIR filter is $500 \mathrm{~Hz}$ and the sampling frequency is $8000 \mathrm{~Hz}$.

4a) Initial coefficient value $h(0)$ has been calculated by $h_{d}(0) \times w_{h}(0)$, assuming $h_{d}(0)=\frac{2 f c}{F s}$ and $w_{h}(0)=0.54-0.46$

Here the coefficient values from $\mathrm{h}(0)$ to $\mathrm{h}(52)$ for the $53^{\text {rd }}$ order FIR low pass filter are -

$[\mathrm{h}(0)=0.010000, \mathrm{~h}(1)=0.010154, \mathrm{~h}(2)=0.010507, \mathrm{~h}(3)=0.010772, \ldots, \mathrm{h}(49)=0.000273, \mathrm{~h}$ $=(50) 0.000420, \mathrm{~h}(51)=0.000481, \mathrm{~h}(52)=0.000490]$

Using the convolution sum formula the output values of the 53rd order FIR filter $y(n)$ can be obtained for $h(0)=h_{d}(0) \times w_{h}(0)$ as-

$[\mathrm{y}(0)=0.000000, \mathrm{y}(1)=0.001951, \mathrm{y}(2)=0.005808, \mathrm{y}(3)=0.011491, \ldots, \mathrm{y}(93)=-0.083662$, $\mathrm{y}(94)=-0.145581,-\mathrm{y}(95)=0.187652, \mathrm{y}(96)=(0.000000]$

The waveform is -

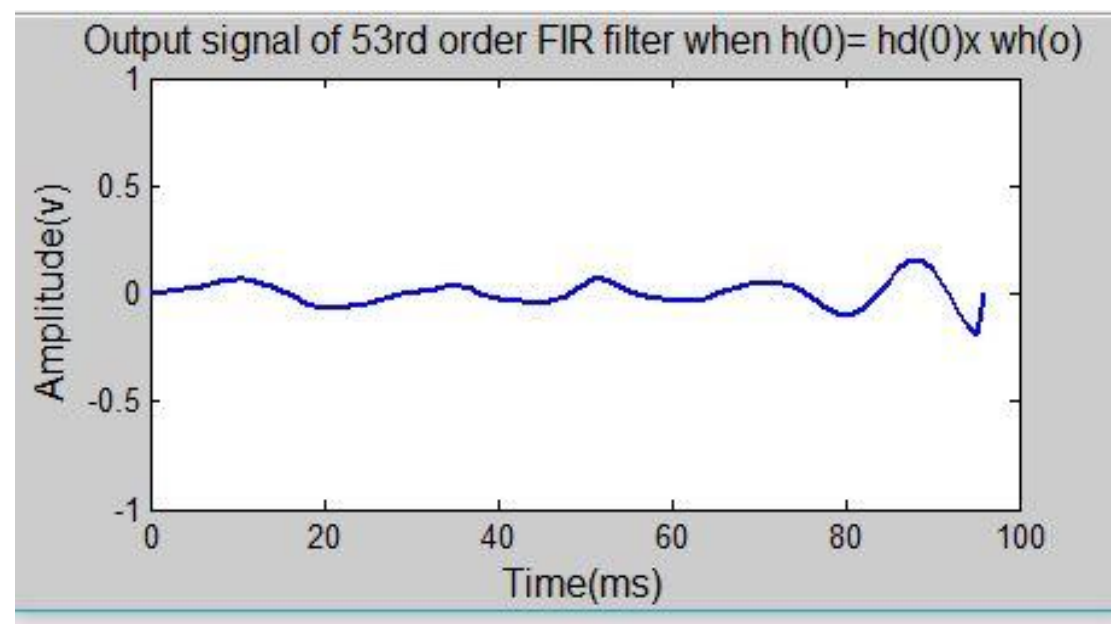

Figure 6a Output waveform of 53rd order low pass filter

$$
\left[\mathrm{h}(0)=\mathrm{h}_{\mathrm{d}}(0) \times \mathrm{w}_{\mathrm{h}}(0)\right]
$$

4b) Here initial coefficient value $h(0)$ has been calculated only by $h_{d}(0)$ without multiplication of window sequence.

The coefficient values from $\mathrm{h}(0)$ to $\mathrm{h}(52)$ for the $53^{\text {rd }}$ order FIR low pass filter are -

$[\mathrm{h}(0)=0.125000, \mathrm{~h}(1)=0.010154, \mathrm{~h}(2)=0.010507, \mathrm{~h}(3)=0.010772, \ldots, \mathrm{h}(49)=0.000273$, $\mathrm{h}(50)=0.000420, \mathrm{~h}(51)=0.000481, \mathrm{~h}(52)=0.000490]$

Using the convolution sum formula the output values of the 53rd order FIR filter $y(n)$ can be obtained for $h(0)=h_{d}(0)$ as-

$[\mathrm{y}(0)=0.000000, \mathrm{y}(1)=0.024386, \mathrm{y}(2)=0.049816, \mathrm{y}(3)=0.075382, \ldots, \mathrm{y}(93)=-0.189908$, $\mathrm{y}(94)=-0.226898, \mathrm{y}(95)=-0.231661, \mathrm{y}(96)=0.000000]$

The waveform is - 


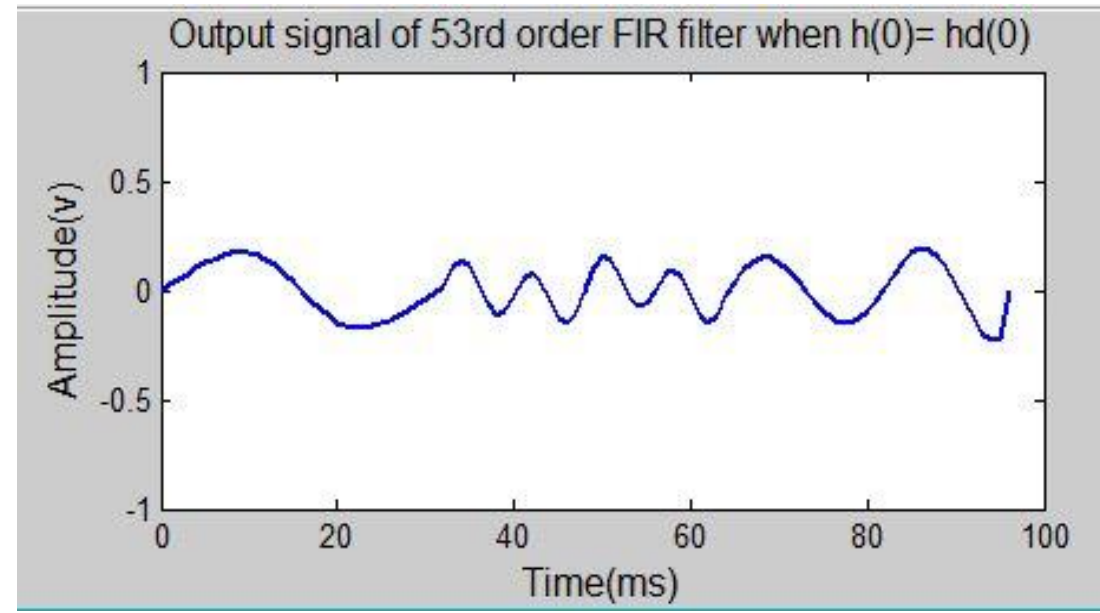

Figure 6b Output waveform of 53rd order low pass filter

$$
\left[\mathrm{h}(0)=\mathrm{h}_{\mathrm{d}}(0)\right]
$$

In this Case-4, it has been observed that as the order of the filter is increased the gain has been decreased and the filter works better to some extent when the first coefficient value $h(0)$ is taken as $h_{d}(0) \times w_{h}(0)$.

The implementation of an FIR filter can be done using any programming language or specific software tools. In the DSP platform there are also various application specific instructions like MAC, FIRS, MACD, etc.

Some specific instructions of the Texas DSP Processor TMS320C5416 can be used as

MAC *AR2-, *AR3+, A

Here AR2 points sample values of the input signal, AR3 points coefficient values and A points the Accumulator which is used to store the filter output values. In this instruction AR2 values decrements, AR3 values increments and then multiplied, added (depending upon the values of previous RPT instruction) and saved in the Accumulator.

Another instruction for the implementation of a symmetrical FIR filter can be used as

FIRS AR2+, AR3-, COEF

Here AR2 and AR3 points to input signal values of symmetrical FIR filter and COEF points the coefficient values. In this instruction AR2 values increments, AR3 values decrements and then added (depending upon the number of values of input signals) and multiplied with the corresponding coefficient values.

\section{CONCLUSION}

It is found that for $23^{\text {rd }}, 33^{\text {rd }}$ and $53^{\text {rd }}$ order filter, the desired $250 \mathrm{~Hz}$ and $500 \mathrm{~Hz}$ outputs are available from the output of the filter and $1000 \mathrm{~Hz}$ signal is attenuated when coefficient values are calculated as $h_{d}(0) \times w_{h}(0)$.

In case of $11^{\text {th }}$ order filter, the desired $250 \mathrm{~Hz}$ and $500 \mathrm{~Hz}$ outputs are available from the output of the filter and $1000 \mathrm{~Hz}$ signal is suppressed when the first coefficient value $h(0)$ is taken as $h_{d}(0)$ only. But for $11^{\text {th }}$ order filter $1000 \mathrm{~Hz}$ signal has not been suppressed well when the first coefficient value $h(0)$ is calculated as $h_{d}(0) \times w_{h}(0)$.

So, it is understood that for designing of FIR filter using the convolution sum formula an appropriate parameter specially for $\mathrm{h}(0)$ to be incorporated according to the order of filter which will determine the proper filter output. 


\section{ACKNOWLEDGEMENT}

For this present work, the author is grateful to Sands Instrumentation Private Ltd., Chennai for their help when the author had undergone a Project on DSP based on Texas TMS320C54x Processor in the year 2004.

\section{REFERENCES}

[1] J.G. Proakis and D.G. Manolakis, Digital signal processing: Principles, algorithms, and applications (New Delhi: Pearson Education, p-664, 2007).

[2] M Vlcek, P. Zahradnik, and R. Unbehauen, Analytical design of FIR filters, IEEE Transactions on Signal Processing, 48(9), 2000, 2705- 2709.

[3] A. V. Oppenhiem and R.W. Schafer, Digital signal processing (New Delhi: Prentice Hall India Private Limited, p-239, 1999).

[4] S. Salivahanan, A. Vallavaraj and C. Gnanapriya, Digital signal processing (New Delhi: Tata McGraw-Hill Publishing Company Limited, p-405, 2005).

[5] B.P. Lathi, Signal processing \& linear systems (New Delhi: Oxford University Press, p-766, 2006).

[6] P.S.R Diniz, E.A.B da Silva and S.L. Netto, Digital signal processing: system analysis and design (Delhi: Cambridge University Press, p-279, 2017).

[7] A. Chandra, and S. Chattopadhyay, Design of hardware efficient FIR filter: A review of the state-of-the-art approaches, Engineering Science and Technology, an International Journal, 19(1), 2016, 212-226.

[8] S.K. Mitra, Digital signal processing: a computer - based approach (New Delhi: Tata McGrawHill Publishing Company Limited, p-422, 2000).

[9] L.R. Rabiner and B. Gold, Theory and application of digital signal processing (New Delhi: Prentice Hall of India Private Limited, p-93, 2003).

[10] B. Venkataramani and M. Bhaskar, Digital signal processors: architecture, programming and applications (New Delhi: Tata McGraw-Hill Publishing Company Limited, p-13, 2003). 